\title{
Liver Transplantation for Unresectable Hepatic Alveolar Echinococcosis
}

DOI: $10.17691 / \mathrm{stm} 2017.9 .1 .16$

Received November 15, 2016

A.I. Artemyev, MD, PhD, Head of the Surgical Department, Center for Surgery and Transplantology;

E.V. Naydenov, MD, PhD, Surgeon, Surgical Department, Senior Researcher, Laboratory of Novel Surgical Technologies, Center for Surgery and Transplantology;

D.A. Zabezhinsky, MD, PhD, Surgeon, Surgical Department, Center for Surgery and Transplantology;

K.K. Gubarev, MD, PhD, Head of the Surgical Department of the Coordination Center

of Human Organs and/or Tissues, Center for Surgery and Transplantology;

I.Y. Kolyshev, MD, PhD, Associate Professor, Department of Surgery with Courses of Oncology, Endoscopy,

Surgical Pathology, Clinical Transplantology and Organ Donation;

V.S. Rudakov, Surgeon, Surgical Department of the Coordination Center of Human Organs and/or Tissues, Center for Surgery and Transplantology;

M.V. Shabalin, Surgeon, Surgical Department, Center for Surgery and Transplantology;

V.V. Shcherbin, Surgeon, Surgical Department, Center for Surgery and Transplantology;

A.N. Bashkov, Head of the Radiation and Radioisotope Diagnosis Department;

S.E. Voskanyan, MD, DSc, Deputy Chief for Surgery, Head of the Center for Surgery and Transplantology,

Head of the Department of Surgery with Courses of Oncology, Endoscopy, Surgical Pathology,

Clinical Transplantology and Organ Donation

State Research Center - A.I. Burnazyan Federal Medical and Biophysical Center of the Federal Medical and Biological Agency of Russia, 23 Marshal Novikov St., Moscow, 123098, Russian Federation

The aim of the investigation was to assess the immediate and long-term results of the liver transplantation in patients with unresectable hepatic alveolar echinococcosis.

Materials and Methods. 22 liver transplantations were performed in the Center for Surgery and Transplantology of the A.I. Burnazyan Federal Medical and Biophysical Center between January 2011 and December 2016 for unresectable liver disease. Liver segments (the right liver lobe in all cases) from living related donors were transplanted to 21 patients, a posmortal donor liver was transplanted to 1 female patient. 16 patients $(72.7 \%)$ had parasitic invasion of the inferior vena cava. All operations were done in R0 variant. Reconstruction of the great vessels was performed by synthetic PTFE-conduits if autoplasty was not feasible.

Results. The duration of surgery was $430(390-480) \mathrm{min}$. The intraoperative blood loss amounted to $1,500(1,300-2,200) \mathrm{ml}, \mathrm{cold}$ ischemia lasted $30(25-45) \mathrm{min}$. The morbidity rate of postoperative complications made up 45.4\%. Biliary complications (Grade A, B, ISGLS, 2011) prevailed. Mortality rate was equal to $4.5 \%$. The length of postoperative hospital stay averaged out to 20 (15-23.5) bed days. Long-term survival rate comprised $100 \%$. Maximal follow-up period was 58 months.

Conclusion. Liver transplantation with resection and reconstruction of the great vessels, including resection of the inferior vena cava and even the right atrium, may be the only radical method of treating unresectable hepatic alveolar echinococcosis, making it possible to provide satisfactory immediate and long-term results of surgical treatment of the patients seemingly doomed to death. These interventions should be performed only in highly specialized centers with a developed program of surgical hepatology and liver transplantation.

Key words: hepatic alveolar echinococcosis; great vessel resection; inferior vena cava; liver transplantation.

Alveolar echinococcosis is a parasitic disease caused by Echinococcus multilocularis larvae that most commonly affects the liver [1-6] forming a tumor-like injury, which possesses the ability to infiltrative growth, invasion of the main vessels of the portal and caval systems, biliary ducts, adjacent organs and tends to form distal metastases by hematogenic or lymphogenic way $[1-4,6]$. Endemic regions of alveolar echinococcosis are Western Siberia, Far East, Central Asia, Central Europe, Alaska, North Canada, China [6, 7].
The only way of liver alveococcosis treatment nowadays is surgical $[4,8]$. However, the disease is often diagnosed in the late stages when the parasite reaches large sizes or mechanical jaundice develops, since patients do not have any symptoms of the disease in the early stages when resection of the liver is feasible [4, 6, 9-11]. Due to these factors, operations for alveolar echinococcosis are characterized by a large extent, are connected with reconstructive and plastic interventions on the great vessels and biliary ducts [12].

For contacts: Evgeny V. Naydenov, e-mail: e.v.naydenov@mail.ru 
Standard radical liver resection becomes hardly feasible in the situations with a large volume of the damaged parenchyma, invasion of the afferent and/or efferent hepatic vessels, retrohepatic segment of the inferior vena cava (IVC), and the right atrium [4, 6, 13, 14], often requiring orthotopic liver transplantation, which enables complete removal of the parasitic tumor, resection and plastic surgery of the great vessels and may be regarded as a principle method of the radical treatment in the socalled unresectable alveolar echinococcosis of the liver [3, 6, 15-17].

The aim of the investigation was to assess the immediate and long-term results of the liver transplantation in patients with unresectable hepatic alveolar echinococcosis.

Materials and Methods. 22 liver transplantations were performed in the Center for Surgery and Transplantology of the State Research Center A.I. Burnazyan Federal Medical and Biophysical Center between January 2011 and December 2016 for unresectable liver disease. Liver segments (the right liver lobe in all cases) from living related donors were transplanted to 21 patients; a postmortal donor liver was transplanted to 1 female patient. Parasitic invasion of the IVC was found in 16 patients $(72.7 \%)$, invasion of the right atrium in 7 patients (31.8\%) (Figure 1).
18 patients underwent nonradical surgical treatment in the past (nonradical liver resection, morcellation of alveococcus, drainage of the alveococcus decay cavity, and others).

Jaundice on admission was noted in 7 patients (31.8\%).

There were 15 women and 7 men among the patients aged from 28 to 51 years (median 36 ).

The study complies with the Declaration of Helsinki (the Declaration was passed in June 1964, Helsinki, Finland, and revised in October 2000, Edinburg, Scotland) and was performed following approval by the Ethic Committee of State Research Center - A.I. Burnazyan Federal Medical and Biophysical Center. Written informed consent was obtained from every patient.

All operations were done in the R0 variant (Figure 2). Invasion of the parasitic process to the adjacent organs was found in 14 patients (63.6\%) and, in this connection, resection of the diaphragm was performed in 10 patients, right-sided adrenalectomy in 1 patient, resection of the pericardium in 4 patients, 1 stomach resection, 1 duodenum resection, 2 nephroadrenalectomy on the right.

No metastases of alveococcus were revealed.

Great vessels plasty, including IVC, was done using PTFE-conduits if autoplasty was not feasible, in case of
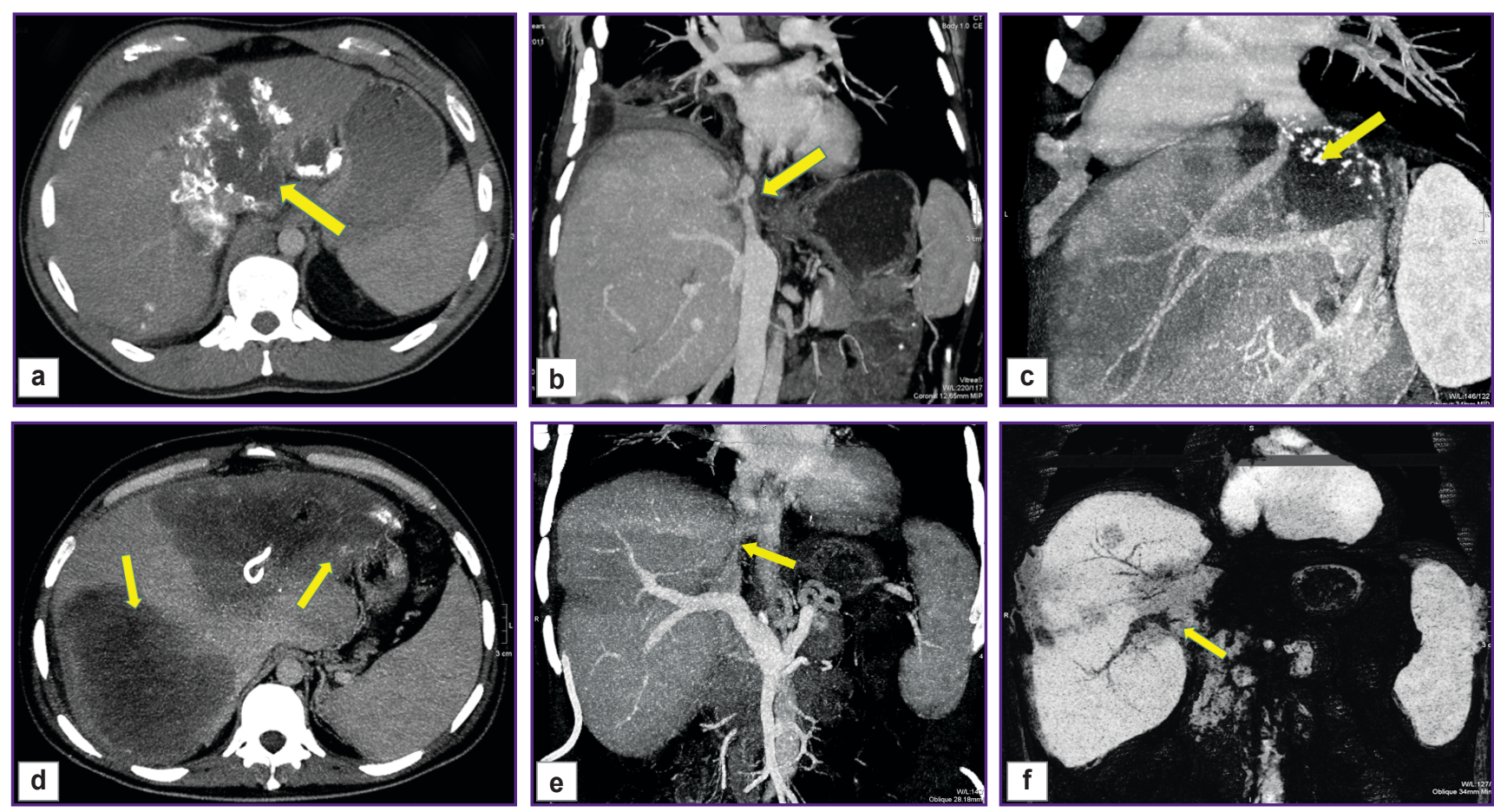

Figure 1. CT image of unresectable liver alveococcosis: (a) parasitic liver damage with invasion of hepatic venous confluence, inferior vena cava (IVC), left lobe portal vein; (b) parasitic liver damage with invasion of IVC at the level of its entry to the right atrium; (c) parasitic liver damage with invasion of hepatic venous confluence and IVC; (d) parasitic damage of both hepatic lobes with extension to the caval hilum, involvement of hepatic veins, right and left portal veins, IVC, left hepatic artery, right adrenal gland, invasion of the right kidney; (e), (f) parasitic liver damage with involvement of the hepatic caval hilum, hepatic veins, IVC, right portal vein, right hepatic artery, bifurcation of the intrahepatic bile ducts, great vessels, antral part of the stomach 

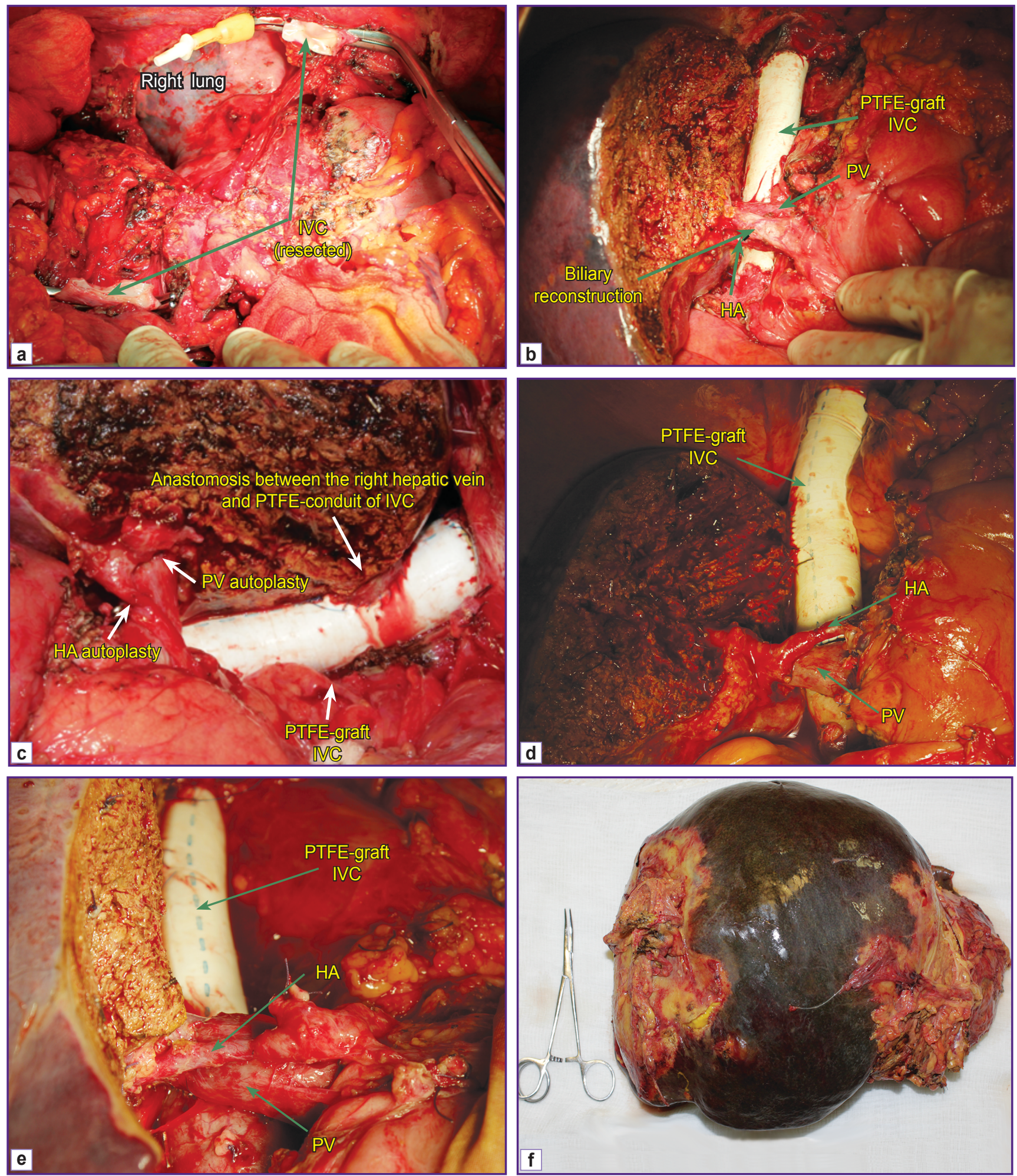

Figure 2. Transplantation of the right hepatic lobe with resection and prosthetic replacement of the inferior vena cava (IVC) with PTFE-conduit: (a) hepatectomy with resection of IVC, right diaphragm dome; (b)-(e) transplantation of the right hepatic lobe from a living related donor, IVC plasty using PTFE-conduit; (f) bilobar parasitic liver invasion (preparation). PV: portal vein; HA: hepatic artery

the right atrium resection right atrium-caval prosthetic surgery with PTFE-conduits was performed (See Figure 2).
Dissection of the hepatic parenchyma was accomplished by bipolar coagulation with targeted ligation of the vascular and ductal structures. 
Postoperative liver failure was determined in compliance with the criteria of liver function evaluation after transplantation suggested by Olthoff et al. [18].

The rate and severity of biliary complications in the postoperative period were assessed according to the ISGLS recommendations [19].

All patients received Albendazole for 6 months in the postoperative period.

Quantitative data are presented in the form of Median (interquartile range). The results of the investigation were processed using Statistica 10.0 applied program package (StatSoft Inc., USA) [20].

Results. The duration of the operation amounted to 430 (390-480) $\mathrm{min}$, the volume of the intraoperative blood loss was equal to $1,500(1,300-2,200) \mathrm{ml}$, the cold ischemia duration was $30(25-45) \mathrm{min}$.

The morbidity rate of postoperative complications was equal to $45.4 \%$. Among them 4 patients were with biliary complications (Grade A, B; ISGLS, 2011); 2 patients with intra-abdominal bleeding requiring relaparotomy and bleeding arrest; 2 cases of hospital pneumonia; 3 cases with hydrothorax demanding drainage or US-controlled puncture of the pleural cavity; and 2 patients with ascites requiring US-controlled drainage of the abdominal cavity.

In 3 patients bilomas found in the abdomen required US-controlled drainage, in 1 patient transdrainage bile leakage was noted.

An intrapleural bleeding developed in 1 patient and required relaparotomy, sanation and hemostasis, later there formed a hematoma of the pleural cavity which was treated by the US-controlled drainage. A crisis of transplant rejection developed in 1 patient who had to be administered a pulse therapy.

Mortality rate amounted to $4.5 \%$ : one woman died of profuse gastrointestinal bleeding from acute stress ulcers of the stomach and duodenum on day 16 after the operation.

The length of hospital stay after liver transplantation amounted to 20 (15-23.5) bed days. Long-term survival after liver transplantation was $100 \%$, maximal follow-up period lasted 58 months.

Discussion. Alveolar echinococcosis of the liver is a parasitic disease resembling malignant tumor in its growth and extension [1-6]. If not radically treated, the mortality rate is usually $90 \%$ within 10 years after being diagnosed [3], however, radical surgical intervention is feasible only in $35 \%$ of these patients due to a late diagnosing of the disease $[3,4,6,13,14,21]$. The main and frequently the only way of radical treatment of patients with unresectable liver alveococcosis is liver transplantation $[3,6,15-17,22]$, however, the technical complexities of the operation due to parasitic invasion of the great vessels, IVC, right atrium, adjacent structures and organs, the previous non-radical surgical interventions, as well as shortage of donor organs, limit the feasibility of liver transplantation.

Little experience has been acquired in the world in the field of liver transplantation for unresectable alveococcosis. It is likely to be connected with the epidemicity of the disease - Echinococcus multilocularis is extremely rarely encountered in the countries with the developed program of liver transplantation. In our Center 22 liver transplantations have been performed in the patients with unresectable alveococcosis, a liver fragment was transplanted from a living related donor to 21 of them. The data presented seem to be the largest single-center experience in the world.

The results obtained enable us to declare the necessity and feasibility of the radical surgical treatment of unresectable liver alveococcosis regardless of the invasion of the great vessels, liver hilum, IVC, right atrium and adjacent structures and organs. Reconstruction of IVC after hepatectomy with the resection of the retrohepatic IVC segment, involved in the pathological process, is feasible by means of synthetic PTFE-conduits.

Conclusion. Liver transplantation with resection and reconstruction of the great vessels, including resection of inferior vena cava, and even the right atrium, may be the only radical method of treating unresectable hepatic alveolar echinococcosis making it possible to provide satisfactory immediate and long-term results of the surgical treatment of patients seemingly doomed to death. These interventions should be performed only in highly specialized centers with a developed program of surgical hepatology and liver transplantation.

Study Funding and Conflicts of Interest. The work was not supported by any source, and there are no conflicts of interest related to this study.

\section{References}

1. Shalimov A.A., Shalimov S.A., Nechitaylo M.E., Domanskiy B.V. Khirurgiya pecheni i zhelchevyvodyashchikh putey [Surgery of the liver and bile ducts]. Kiev: Zdorov'e; 1993; $512 \mathrm{p}$.

2. Veronsky G.I. Surgical treatment of liver alveococcosis. Annaly khirurgicheskoy gepatologii 1997; 2: 15-19.

3. Ozdemir F., Ince V., Barut B., Onur A., Kayaalp C., Yilmaz S. Living donor liver transplantation for echinococcus alveolaris: single-center experience. Liver Transp/ 2015; 21(8): 1091-1095, https://doi.org/10.1002/t.24170.

4. Skipenko O.G., Shatverian G.A., Bagmet N.N., Chekunov D.A., Bedzhanian A.L., Ratnikova N.P., Zavoikin V.D. Alveococcosis of liver: retrospective analysis of treatment of 51 patients. Khirurgiya. Zhurnal im. N.I. Pirogova 2012; 12: 4-13.

5. Milonov O.B., Smirnov V.A. Vnutrennie zhelchnye svishchi. Naruzhnye $i$ vnutrennie svishchi $v$ khirurgicheskoy klinike [internal biliary fistulae. External and internal fistulae in the surgical clinic]. Moscow: Meditsina; 1982; p. 125-151.

6. Porshennikov I.A., Bykov A.Y., Pavlik V.N., Kartashov A.S., Shchekina E.E., Korobeynikova M.A., Yushina E.G. Liver transplantation and liver resection with vascular reconstruction for advanced alveococcosis. Annaly khirurgicheskoy gepatologii 2016; 21(2): 11-24.

7. Craig P.S. Epidemiology of human alveolar echinococcosis in China. Parasitol Int 2006; 55: S221-S225, https://doi.org/10.1016/j.parint.2005.11.034. 
8. Cheremisinov O.V. Kompleksnaya differentsial'naya luchevaya diagnostika pri khirurgicheskom lechenii al'veokokkoza i ekhinokokkoza. Avtoref. dis. ... dokt. med. nauk [Complex differential radiation diagnosis in surgical treatment of alveococcosis and echinococcosis]. Moscow; 2005.

9. Buttenschoen K., Gruener B., Carli Buttenschoen D., Reuter S., Henne-Bruns D., Kern P. Palliative operation for the treatment of alveolar echinococcosis. Langenbecks Arch Surg 2009; 394(1): 199-204, https://doi.org/10.1007/s00423-0080367-6.

10. Kawamura N., Kamiyama T., Sato N., Nakanishi K., Yokoo H., Kamachi H., Tahara M., Yamaga S., Matsushita M., Todo S. Long-term results of hepatectomy for patients with alveolar echinococcosis: a single-center experience. J Am Coll Surg 2011; 212(5): 804-812, https://doi.org/10.1016/j. jamcollsurg.2011.02.007.

11. Moore J., Gupta V., Ahmed M.Y., Gociman B. Hydatid cyst disease: optimal management of complex liver involvement. South Med J 2011; 104(3): 222-22, https://doi. org/10.1097/smj.0b013e318205e686.

12. Zagaynov V.E., Kiselev N.M., Gorokhov G.G., Vasenin S.A., Bel'skiy V.A., Shalapuda V.I., Rykhtik P.I. Modern methods of surgical treatment of diffuse liver alveococcosis. Annaly khirurgicheskoy gepatologii 2016; 21(1): 44-52.

13. Ayifuhan A., Tuerganaili A., Jun C., Ying-Mei S., Xiang-Wei L., Hao W. Surgical treatment for hepatic alveolar echinococcosis: report of 50 cases. Hepatogastroenterology 2012; 59(115): 790-793, https://doi.org/10.5754/hge10545.

14. Buttenschoen K., Carli Buttenschoen D., Gruener B., Kern P., Beger H.G., Henne-Bruns D., Reuter S. Long-term experience on surgical treatment of alveolar echinococcosis. Langenbecks Arch Surg 2009; 394(4): 689-698, https://doi. org/10.1007/s00423-008-0392-5.

15. Kern P., Wen H., Sato N., Vuitton D.A., Gruener B., Shao Y., Delabrousse E., Kratzer W., Bresson-Hadni S. WHO classification of alveolar echinococcosis: principles and application. Parasitol Int 2006; 55: S283-S287, https://doi. org/10.1016/j.parint.2005.11.041.
16. Brunetti E., Kern P., Vuitton D.A. Expert consensus for the diagnosis and treatment of cystic and alveolar echinococcosis in humans. Acta Trop 2010; 114(1): 1-16, https://doi.org/10.1016/j.actatropica.2009.11.001.

17. Voskanyan S.E., Artem'ev A.I., Naydenov E.V., Zabezhinskiy D.A., Chuchuev E.S., Rudakov V.S., Shabalin M.V., Shcherbin V.V. Transplantation technologies for surgical treatment of the locally advanced hepatic alveococcosis with invasion into great vessels. Annaly khirurgicheskoy gepatologii 2016; 21(2): 25-31.

18. Olthoff K.M., Kulik L., Samstein B., Kaminski M., Abecassis M., Emond J., Shaked A., Christie J.D. Validation of a current definition of early allograft dysfunction in liver transplant recipients and analysis of risk factors. Liver Transplantation 2010; 16(8): 943-949, https://doi.org/10.1002/lt.22091.

19. Koch M., Garden O.J., Padbury R., Rahbari N.N., Adam R., Capussotti L., Fan S.T., Yokoyama Y., Crawford M., Makuuchi M., Christophi C., Banting S., Brooke-Smith M., Usatoff V., Nagino M., Maddern G., Hugh T.J., Vauthey J.N., Greig P., Rees M., Nimura Y., Figueras J., DeMatteo R.P., Büchler M.W., Weitz J. Bile leakage after hepatobiliary and pancreatic surgery: a definition and grading of severity by the International Study Group of Liver Surgery. Surgery 2011; 149(5): 680-688, https://doi.org/10.1016/j.surg.2010.12.002.

20. Rebrova O.Yu. Once again, on the quality of statistical analysis in medical publications: current status of the problem, recommendations, peer reviewing. Meditsinskie tekhnologii. Otsenka i vybor 2014; 1(15): 8-10.

21. Koch S., Bresson-Hadni S., Miguet J.P., Crumbach J.P., Gillet M., Mantion G.A., Heyd B., Vuitton D.A., Minello A., Kurtz S.; European Collaborating Clinicians. Experience of liver transplantation for incurable alveolar echinococcosis: a 45-case European collaborative report. Transplantation 2003; 75(6): 856-863, https://doi.org/10.1097/01.tp.0000054230.63568.79.

22. Bresson-Hadni S., Vuitton D.A., Bartholomot B., Heyd B., Godart D., Meyer J.P., Hrusovsky S., Becker M.C., Mantion G., Lenys D., Miguet J.P. A twenty-year history of alveolar echinococcosis. Eur J Gastroenterol Hepatol 2000; 12(3): 327336, https://doi.org/10.1097/00042737-200012030-00011. 